\title{
AIRBORNE DIFFERENTIAL ABSORPTION AND HIGH SPECTRAL RESOLUTION LIDAR MEASUREMENTS FOR CIRRUS CLOUD STUDIES
}

\author{
Silke Gross ${ }^{1 *}$, Andreas Schaefler ${ }^{1}$, Martin Wirth ${ }^{1}$, Andreas Fix ${ }^{1}$ \\ ${ }^{1}$ Institute of Atmospheric Physics, German Aerospace Center (DLR), 82234 Oberpfaffenhofen, Germany, \\ *Email: silke.gross@dlr.de
}

\begin{abstract}
Aerosol and water vapor measurements were performed with the lidar system WALES of the German Aerospace Center (DLR) onboard the German research aircraft G550-HALO during the HALO Techno-Mission in October and November 2010 and during the ML-Cirrus mission in March and April 2014 over Central Europe and the North Atlantic region. Curtains composed of lidar profiles beneath the aircraft show the water vapor mixing ratio and the backscatter ratio. Temperature data from ECMWF model analysis are used to calculate the relative humidity above ice (RHi) in the 2-D field along the flight track to study the RHi distribution inside and outside of cirrus clouds at different stages of cloud evolution.
\end{abstract}

\section{INTRODUCTION}

Although cirrus clouds have a large impact on the Earth's climate system [1] [2], especially their radiative properties are still only insufficiently understood [3][4]. The radiative properties of cirrus clouds highly depend on their microphysical composition [5], e.g. the ice crystal shape, the size distribution and the number concentration, which are strongly dependent on ambient vertical movement [6]. To improve our knowledge of cirrus clouds a better understanding of the micro- and macro-physical properties of cirrus clouds is mandatory. Airborne differential absorption lidar (DIAL) measure the 2dimensional atmospheric structure along the flight path and thus provide valuable information to study the macro-physical properties as well as the fine-structure of cirrus clouds. Furthermore the combination of DIAL measurements with additional temperature information (e.g. from ECMWF model analysis) enable the investigation of relative humidity distribution and icesupersaturation inside and outside of cirrus clouds, which is a crucial measure for cirrus cloud formation and evolution processes [7].

We present measurements of cirrus cloud properties performed with the DLR differential absorption and high spectral resolution lidar (HSRL) system WALES during the HALO Techno-Mission in autumn 2010 and during the ML_Cirrus mission in spring 2014. We provide $\mathrm{RHi}$ curtains beneath the HALO flight path from combined lidar water vapor measurements and temperature data from ECMWF model analysis, and investigate the RHi distribution inside and outside of cirrus clouds. A special focus of our studies is on the analysis of differences in RHi distribution for different types of cirrus clouds and cirrus cloud evolution stages.

\section{METHODOLOGY}

\subsection{Differential Absorption Lidar WALES}

The multi-wavelength lidar system WALES of the DLR-Institute for Atmospheric Physics is capable to emit simultaneously four wavelengths, three online and one offline, in the water vapor absorption band around $935 \mathrm{~nm}$. Additionally to the $935 \mathrm{~nm}$ channel, the system is equipped with polarization sensitive aerosol channels at $532 \mathrm{~nm}$ and $1064 \mathrm{~nm}$, the first with high spectral resolution capabilities using an iodine filter in the detection path [8]. A detailed technical description of the system was done by [9]. An analysis of the systems accuracy can be found in [10].

\subsection{HALO}

The new German research aircraft HALO (High Altitude and LOng range) is based on a modified Gulfstream G550. It is operated by the Flight Department of the DLR, Oberpfaffenhofen. HALO has a flight range of more than $8000 \mathrm{~km}$, a flight time of more than $10 \mathrm{~h}$, and a maximum cruising height of more than $15 \mathrm{~km}$. Therefore measurements with WALES on HALO achieve the necessary distance to cirrus cloud tops to 
prevent saturation of the detector units due to strong backscattered light from the clouds.

\subsection{ML_Cirrus mission}

The Mid-Latitude Cirrus mission ML_Cirrus is a joint activity of different German research centers and universities led by the DLR-Institute of Atmospheric Physics, and took place in March and April 2014. Measurements were performed with a set of remote sensing and in-situ measurements onboard HALO to study aviation induced cloudiness as well as natural mid-latitude cirrus clouds in Central Europe and the North Atlantic. The operational base of HALO during ML Cirrus was Oberpfaffenhofen. Altogether 12 research flights over Germany, the North Atlantic region, and South-Western Europe were carried out. Additional data for cirrus cloud studies are available from the HALO Techno-Mission.

\section{RESULTS - CASE STUDY ON 11 APRIL 2014}

The main focus of the research flight on 11 April was to measure cirrus cloud properties in different stages of cloud evolution. Model simulations indicated rapidly ascending air masses over the extra tropical North-Atlantic region and high cirrus cloud evolution probability north-westerly of Scotland followed by cirrus cloud resolving areas in the region of the English Channel.

To achieve the research aims of this flight, four consecutive flight lags at different altitudes (three for in-situ measurements, and one at high altitude for lidar measurements) were planned parallel to the $500 \mathrm{hPa}$ isobars (see Figure 1).

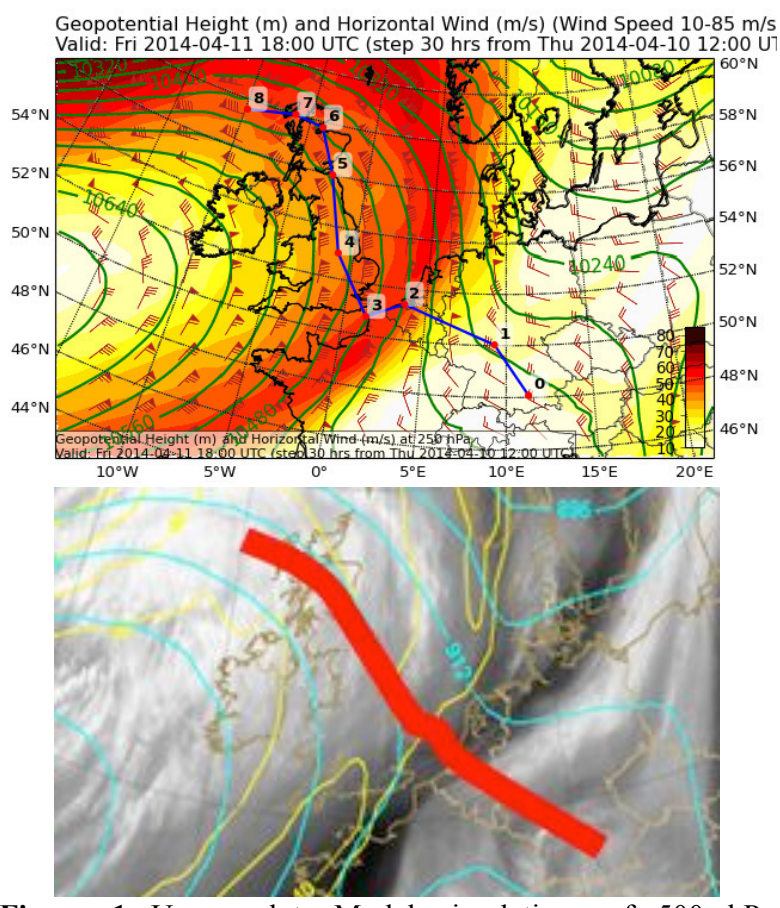

Figure 1 Upper plot: Model simulations of $500 \mathrm{hPa}$ geopotential height and horizontal wind for 11 April 2014, 18 UTC and planned HALO flight path for the fourth flight leg (blue line). Lower plot: water vapor satellite measurements on 11 April 2014 in combination with $500 \mathrm{hPa}$ geopotential height (cyan lines) and HALO flight path for the fourth flight leg (red line).

Figure 2 gives an overview over the lidar measurements during the fourth flight leg of this research flight. It shows the lidar backscatter ratio cross-section at $532 \mathrm{~nm}$. The measurements extend from the formation region of the cirrus cloud at Northern Scotland to the dissolving area over the English Channel.

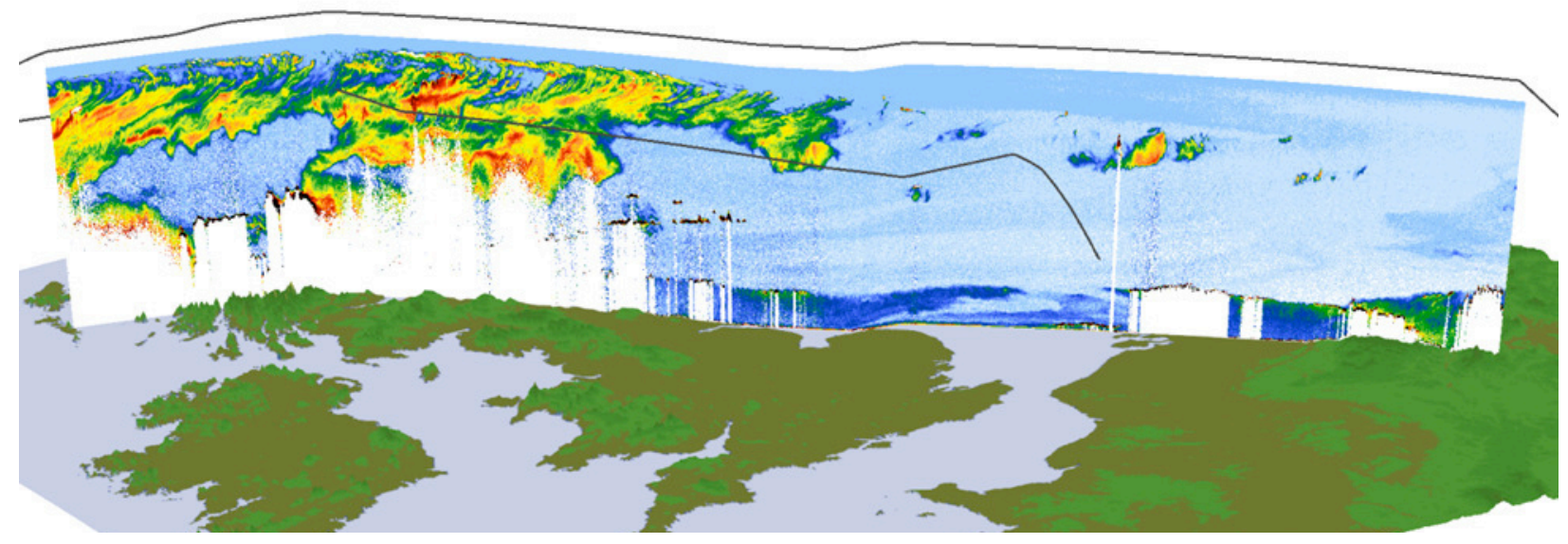

Figure 2 Extinction corrected backscatter ratio at $532 \mathrm{~nm}$ as measured with WALES on HALO on 11 April 2013. 
To study RHi distribution and supersaturation inand outside the cirrus cloud the RHi field along the flight track was calculated using a combination of WALES' water vapor measurements and interpolated ECMWF model temperature data. The applicability of ECMWF model temperature to study cirrus cloud properties was recently investigated by [11]. The RHi cross section along the fourth flight leg is shown in Figure 3.

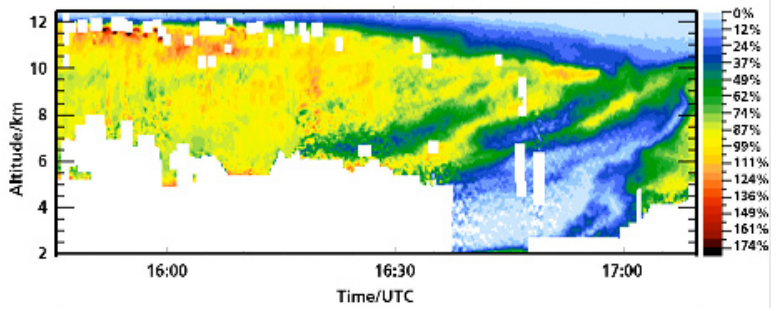

Figure 3 Relative humidity over along the fourth flight leg on 11 April 2014 ice calculated from combined lidar water vapor mixing ratio and ECMWF model analysis temperature data.

The threshold for the decision cloud/no-cloud was set to an empirical value of the backscatter ratio at $532 \mathrm{~nm}$ of 2 . Taking the whole cloud measured on 11 April 2014 into account, the RHi distribution inside the cloud (not shown here) shows highest frequencies for RHi values around $95 \%$, a strong broadening to RHi values below $80 \%$ and a slight broadening to RHi values larger than $120 \%$. To determine the height dependence of RHi within the cirrus cloud, the cloud was divided in height levels of $500 \mathrm{~m}$.

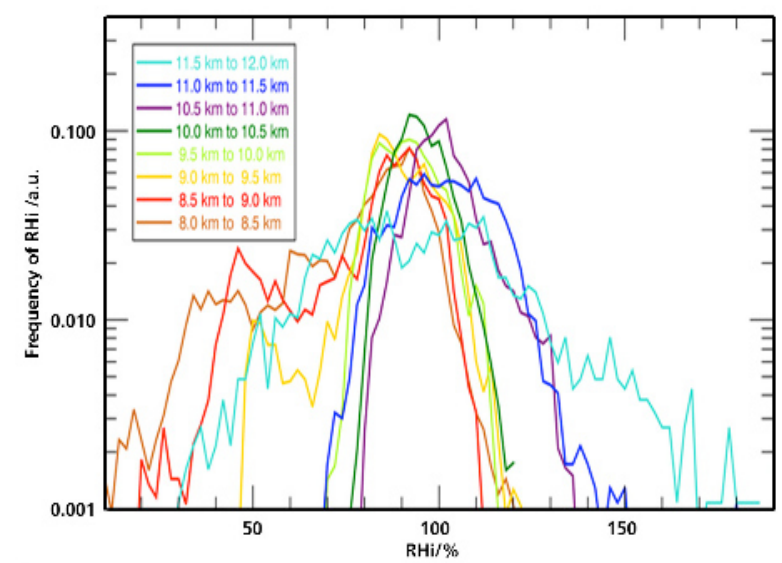

Figure 4 Frequency distribution of the relative humidity over ice dependent on the height level inside the fully developed cirrus cloud.
The RHi values in the mid-part of the cirrus cloud show a narrow distribution with a mean value of about $95 \%$ while the RHi distribution of the lowest cloud layers show a strong broadening towards lower values. Even RHi values smaller $50 \%$ were measured in the lowermost cirrus cloud layers. The highest RHi values were found in the uppermost cloud layers (see Figure 4).
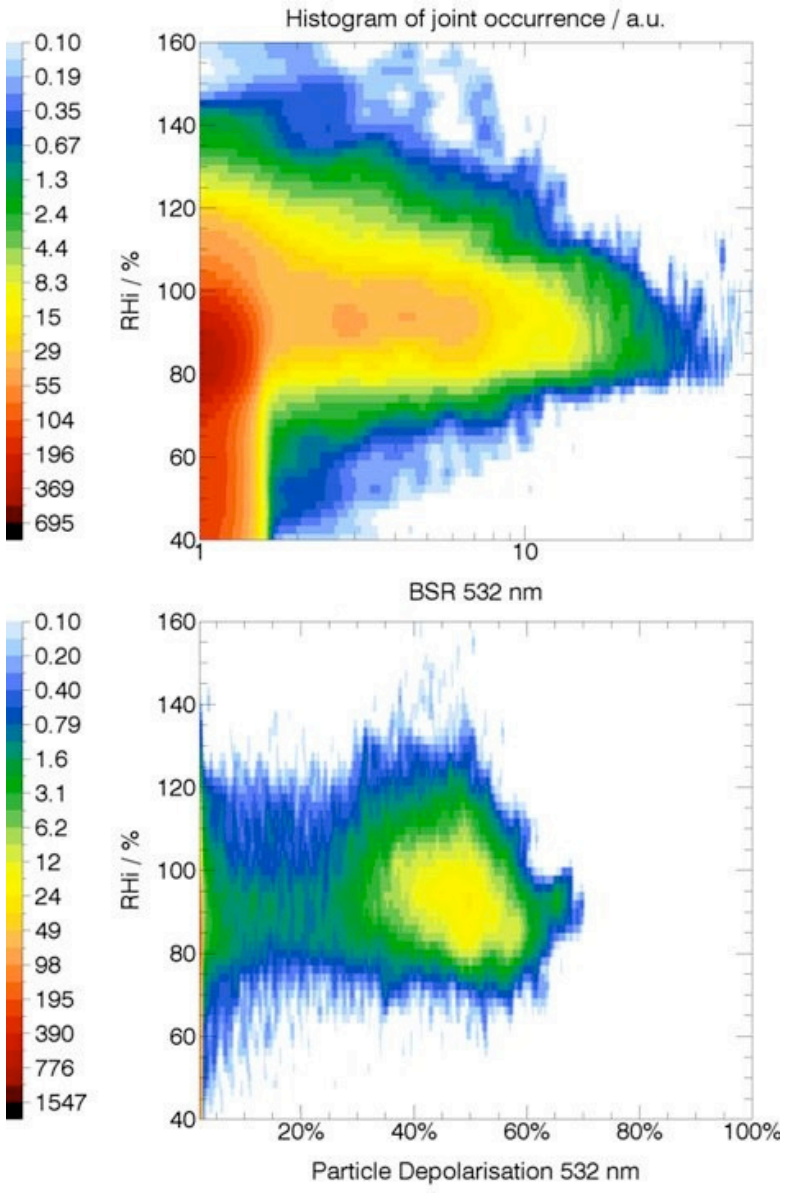

Figure 5 Histogram of joint occurrence of the relative humidity over ice (RHi) and the extinction corrected backscatter ratio (BSR) at $532 \mathrm{~nm}$ (upper plot) and of the RHi and the particle depolarization ratio at $532 \mathrm{~nm}$ (lower plot).

Additional to the analysis of the RHi field along the flight track, correlated measurements of the 2$\mathrm{D}$ distribution of the RHi and the backscatter ratio (BSR), as well as of the RHi and the particle depolarization ratio (PDR) at $532 \mathrm{~nm}$ were performed (Figure 5), showing RHi values near saturation for large BSRs. Outside the cloud high ice-supersaturation up to more than $150 \%$ was found. The PDR inside the cloud mainly ranged between 0.3 and 0.6 with most frequent values 
around 0.5. High RHi values inside the cloud are correlated with quite high PDRs of 0.4 - 0.5.

\section{SUMMARY AND OUTLOOK}

Combined airborne DIAL and HSRL measurements, performed during the HALO Techno-Mission and the ML_Cirrus mission, are used to study the fine-structure and the macrophysical properties of cirrus clouds. RHi fields beneath the flight track, calculated from combined lidar water vapor and ECMWF model analysis temperature data, show large differences in the height dependent RHi distribution within the cirrus cloud for cirrus clouds at different stages of evolution and formation mechanisms, as well as in analysis of ice-supersaturation inside and outside the cirrus clouds.

The measured dataset provides an ideal basis to investigate the properties and differences of cirrus clouds in different stages of evolution and under different meteorological conditions. Therefore the WALES measurements during the ML_Cirrus mission will be systematically analyzed under consideration of the meteorological situation and the age / stage of evolution of the cirrus cloud. Besides our studies concerning ice-supersaturated regions in the vicinity of cirrus clouds, we will investigate the link of $\mathrm{RHi}$ and backscatter intensity to other lidar parameters like the depolarization or extinction-to-backscatter ratio, and we will examine dominant horizontal and vertical scales of the cirrus cloud properties. Our results will be combined with model analyses and in-situ measurements to answer some general questions related to altitude, age, and long term history dependence of the cirrus cloud properties.

\section{ACKNOWLEDGEMENT}

The authors like to thank the staff members of the HALO aircraft of DLR Flight Experiments for preparing and performing the measurement flights.

\section{REFERENCES}

[1] Cox, S. K., 1971: Cirrus clouds and the climate, J. Atmos. Sci., 28, 1513-1515.
[2] Liou, K.-N., 1986: Influence of cirrus clouds on weather and climate processes: a global perspective, Mon. Wea. Rev., 114, 1167-1199.

[3] IPCC, climate change 2007: The scientific basis, Cambridge University Press.

[4] IPCC, climate change 2013: The Physical Science Basis.

[5] Fusina, F., U. Lohmann, and P. Spichtinger (2007). Impact of ice supersaturated regions and thin cirrus on radiation in the midlatitudes, $J$. Geophys. Res., 112, D24S14.

[6] Heymsfield, A, 1977: Preciptitaion development in stratiform ice clouds: A microphysical and dynamical study, J. Atmos. Sci., 34, 367-381.

[7] Heymsfield, A. J., and L. M. Miloshevich, 1995: Relative humidity and temperature influences on cirrus formation and evolution: Observations from wave clouds and FIRE II, $J$. Atmos. Sci., 52, 4302-4326.

[8] Esselborn, M., M. Wirth, A. Fix, M. Tesche, and G. Ehret, 2008: Airborne high spectral resolution lidar for measuring aerosol extinction and backscatter coefficients, Appl. Opt., 47(3), 346-358, doi:10.1364/AO.47.000346.

[9] Wirth, M., A. Fix, P. Mahnke, H. Schwarzer, F. Schrandt, and G. Ehret, 2009: The airborne multi-wavelength h2o-dial wales: system design and performance, Appl. Phys. B: Lasers Opt., 96(1), 201-213, doi:10.1007/s00340-009-3365-7.

[10] Kiemle, C., M. Wirth, A. Fix, G. Ehret, U. Schumann, T. Gardiner, C. Schiller, N. Sitnikow, and G. Stiller, 2008: First airborne water vapor lidar measurements in the tropical upper troposphere and mid-latitudes lower stratosphere: accuracy evaluation and intercomparisons with other instruments, Atmos. Chem. Phys., 8, 52455261.

[11] Groß, S., Wirth, M., Schäfler, A., Fix, A., Kaufmann, S., and Voigt, C., 2014: Potential of airborne lidar measurements for cirrus cloud studies, Atmos. Meas. Tech., 7, 2745-2755, doi:10.5194/amt-7-2745-2014. 